\title{
Systematical Design for the Course of Basis of Surveying Adjustment with for Targeted-oriented Quality Courses
}

\author{
MA Daxi, SHI Xiangfeng, XIAO Haiping \\ Jiangxi University of Science and Technology
}

\begin{abstract}
This article states the concept, feature and construction content of quality course. With the aims and objective of quality course, it describes one of the core courses for mapping and surveying major: basis of survey adjustment. The study aims to explore curriculum systematical reform, curriculum reform content, teaching method and teaching method reform for quality course and contribute as a reference for quality course construction.

Index Terms - quality course, basis of surveying adjustment, curriculum reform

The quality of personnel training reflects the quality of higher education and it is the foundation of university survival and development. Curriculum is the fundamental unit for personnel training. If the content of educational thinking would become part of the teaching and learning eventually, curriculum should be regarded as the bond. In this way, education thinking can be embedded through the contents of course content planning, course design and course aims and objective design. Without curriculum, the concept of education is difficult to achieve, the connotation construction of universities and colleges is unrealistic. Thus, from the perspective of applying innovative talented personnel training, it is necessary to take a close look at the nature and feature of different curriculum with the starting point of quality course construction and driving professional education teaching reform and creating new personnel training mode. These will effectively improving the quality of teaching.

Basis of surveying adjustment is one of the core curriculums for mapping and surveying major. Its methodology has great importance for future professional course as the foundation and it is an indispensable part for mapping and surveying. In addition, the extension of its content directly affects the development of the science of mapping and surveying. Hence, special attention has been paid to curriculum design research and reform. This article focuses on the construction of quality course, with pilot high-standard projects, it explores the reform and construction of systematic design of basis of surveying adjustment course. The preliminary objective is to provide reference to quality course construction.
\end{abstract}

\section{The concept and features of university quality course}

\section{A. The concept of quality course}

According to the "national university quality course evaluation indication system", the concept of quality course refers to courses with excellent standard of teaching and unique teaching method. The system also highlights that quality course must reflect the thinking of modern education, in line with the universal law of nature, science and teaching and should be with distinct teaching effect. Meanwhile, quality course should have significant radiation promotion effect and pilot function.

\section{$B$. The features of quality course}

(1) Demonstration: one of the objectives for quality course construction is to guide university teaching by promote creative teaching and teaching reform, to guide students think independently and creatively.

(2) Scientificity: key content of quality course should be adopted in the framework and system of quality course construction. This is based on the demand of meeting the rules of science development and education rules.

(3) Creativilty: common creativity of quality course are: firstly, it is in line with the concept of updated teaching and in line with the direction of education reform. Secondly, its content should reflect the up-to-date technique, theoretical research and knowledge in particular filed. Third, teaching method and teaching approach should be unique.

(4) Practicability: one of the key features for engineering quality course is practicability. For one thing, curriculum design should be embedded with particular engineering background and with workable technical requirements. For another, teaching content should focus on application and engineering personal training. It is crucial to build up complex practical link.

\section{II . The construction content of university quality course}

The construction content of quality course can be put into following 6 aspects:

(1) Content construction: this is regarded as the core of content construction. For quality courses, the content should be rational, advanced, interesting and should reflect up-to-date technique and research findings and absorbs advanced teaching experience with relevant combination of national economic development need. Content construction for quality courses should be in line with undergraduate curriculum design and in line with the combination of curriculum system reform. It is necessary to handle the relationship between single curriculum and course construction.

(2) Team building: the lectures for most quality course are with rich teaching experience and have adequate research experience. Those professors are responsible for the design and developing work of quality course. In addition, for each quality course it must be equipped with a team of qualified 
teachers and assistant researchers. Research students such as doctors, post-doctors are encouraged to be engaged in teaching and experimental guiding work.

(3) Teaching method and approach construction: this part is regarded as the key point of teaching method and teaching reform. The development of information technology changes teaching method gradually. Compare to traditional teaching methods, intuitive multimedia technology represents teaching content in an easy-understandable way. It makes students absorb teaching content with interest. Meanwhile, the use of network and multimedia technology can improve both the teaching content of science nature of interest, but also enhance the real-time exchange of students and teaching. Hence, teaching outline, exercise and experiment and relevant reference materials for quality courses should be open and be available on the internet. This is called JITT (Just In Time Teaching) approach.

(4) Teaching material construction: teaching material is another key component of quality course. Quality course needs high quality teaching material. Moreover, the teaching material must be systematic. Lecturer or professors with their team draft the teaching material with national and international high quality teaching material resources.

(5) Experiment content construction: experiment and practice are two key components of quality course construction. These are key method to develop students' operational capacity and creativity thinking. Quality course construction requires reform in teaching methods and teaching content. The proportion of integrated and creative experiment would be increased and students are encourage to take part in research events.

(6) Capacity building: it is professor or lecture's duty to teach the students. Universities should encourage professors to contribute in the construction of quality course. Meanwhile, universities should take measures in terms of capacity input so as to secure better construction of quality course. For example, specific funding should be given for quality course construction; select commend teachers and model quality course. In terms of personnel allocation, flexible combination and allocation of lectures and professors should be adopted. In addition, the appraisal and evaluation system for lectures and teachers should be improved. [2]

\section{Design of basis of surveying adjustment reform}

Basis of surveying adjustment is one of the most important curriculums for mapping and survey major. It directly affects the quality of surveying personnel. Thus, in the student training plans, basis of surveying adjustment is always regarded as a compulsory curriculum. Mapping and surveying is a traditional science which is significantly affected by up-todate technology. With the diversification of observation data and observation method, the precise of surveying instrument, the targeted research objective and research methodology are keep updating. [3] The national university mapping surveying teaching committee has decided the direction of this major with the goal of "sound foundation, wide caliber, strong capacity and high quality" with the training mode of "multiskill" innovative personnel.

Obviously, the new technology and surveying method increased the complexity of data processing. From the perspective of output high quality surveying personnel, it is crucial to promote reform to meet the new challenges nowadays. Also, the reform should be practical and workable based on the reality. This could help to improve teaching quality in general and is in line with the demand of new technology development and personnel requirement.

\section{A. Reform of quality course objective}

From the analysis of curriculum reform, the key premise to achieve training qualified personnel is to design a training which can both provide sound theoretical foundation but also with excellent creativity thinking and wide horizon. At present, under the background of major reform, its systematical structure research and reform can be summarized as "improve theoretical basis, develop operational ability, expending application field, chasing up-to-date technology, introducing latest newest research finding". Hence, the construction of quality course can be divided into two stages: theoretical stage and empirical stage. Specific aims and objectives will be designated correspondingly. [4]

\section{B. Reform of quality course content}

As the source of surveying data increases and the application range expends, it leads to the generation of new data processing theory and new methodologies. In order to enable student have sound professional knowledge including master modern surveying data processing methods as much as possible, the following points highlight the principles for quality course reform:

(1) focusing on fundamentality: as one of the core fundamental theoretical course, the objective is to lay sound theoretical basis among students. Thus, the selecting of teaching material should pay special attention to the logic and system of basis professional theories.

(2) Keeping progressiveness: keep pace with the times and the content of quality course should reflect the latest findings and techniques and complement new knowledge to keep progressiveness.

(3) Emphasizing practicability: during teaching students, it is also important to make sure the knowledge should be practical. Hence, selected cases should be derived from surveying empirical work. By enlarging the application range and enhance the understanding of theatrical knowledge, the direction of future development and its application field can be predicted.

(4) Representing scientificalness: the result of quality course can be represented from the organization of quality content. The content of quality courses should represents the rational framework and system of selected courses. The education concept can be embedded in to the teaching. 


\section{Reform of teaching methods and measures}

Teaching method and teaching measures are the key factors to guarantee teaching quality. In order to improve teaching efficiency, multiple teaching methods can be integrated.

(1) Class teaching: as the most widely used teaching method, class teaching focus on basis theoretical teaching of "basis of surveying adjustment". During class teaching, the research key point is how to integrate traditional teaching method and modern teaching method. The basis of surveying adjustment covers a wide range of knowledge of surveying theories, higher mathematics, probability theory, mathematical statistics, liner algebra and theory of matrices. The key features of this course is with large quantity of concepts and many complicated equations. Traditional teaching method is the lecture writes down the process of calculation of particular equations. The advantage of this teaching method is that students can easily follow the calculation procedure and can easily understand the meaning of particular equations. While the disadvantage is that students easily get born with this single teaching method. When adopting multi media teaching, it can draw students' attention while the calculation process would be less clear for students to follow. Thus, by discussing specific topics focusing on how to integrate traditional and modern teaching method and improve teaching efficiency as a whole. Lectures draw up multimedia teaching material with the assistance of blackboard writing. In this way, the teaching content are clear and the teaching forms are flexible. This can not only draw students attention but also increase the information. Three key points should be bear in mind, they are (i) systematic: since in the course, there must be many symbols and equations. By using consistent symbols and for idiomatic usage with relevant explanation, it helps to solve specific problem. (ii) pioneering: on top of secure teaching with the guidance course content, particular research topics and existing issues can be added to the teaching. It may boarder students' horizon and opens up their mind. (iii) associativity: applying new approaches of data processing into new technology study in GIS, GPS or RS field. The associativity also refers to the combination of theoretical and practical, combination of example and case study and combination of teaching and research projects.

(2) Class discussion: after teaching every unit, exercise can be delivered to students so as to exam the teaching result. According to interaction between lecture and students, the lecture can control and change teaching plan and give time for class discussion. The discussion is with particular topics. The lecture guide and organize the student discussion. Meanwhile, lecture can deliver his own ideas based on research findings to broad students' horizon.
(3) Extra tutoring: On top of class teaching and extra lecture and presentations, extra tutoring is another key link to improve teaching quality. For example, Q\&A part after class can help to solve students' question in time. After each class test and reviewing, the lecture can give extra tutoring emphasizing on particular issues. It helps student to master particular theoretical knowledge. In addition, in order to improve teaching method and meeting the development demand, the research on computer assistant teaching on basis of surveying adjustment is necessary. It develops "intelligent computer assistant teaching system". Meanwhile, reform in assistant exercise and test mode is required as well.

(4) Creating interactive platform between lectures and students: make full use of computer network. Under "basis of surveying adjustment" online class, a column for "Q\&A" is opened up. Students can raise questions on Question board. Alternatively, students can write emails to the lectures and the email address are available on the internet as well. Teachers can both answer students' question on the Q\&A board or by replying emails. The Q\&A column is regarded as an effective bridge. It can not only arouse students learning desire but also help lectures collect feedback from students to adjustment teaching plans and teaching content.

\section{Conclusion}

Quality course is established as a key content of "university and higher education teaching quality and teaching reform engineering" project. The goals of this objective is to achieve sharing high quality resources and improve the quality of personnel training and higher education teaching by using modern and information technology methods and teaching management measures. Quality course is a long-term work. The construction of quality course should be embedded in advanced teaching concept, advanced teaching content, advanced teaching facilities and advanced teaching standard. The reform and innovation of the concept of teaching and teaching can sustain the healthy development of university quality course construction and improve teaching quality as a whole.

\section{References}

[1] Zhang,Y.X. Boost "quality engineering" and construction quality course. China Higher Education, 2003(9)

[2] Zhang,X.H., Zeng,H.H. and Wang, D.Q. Enhancing the construction of quality course and promote creative personnel training. China Higher Education, 2012(15).

[3] Zhang,J., Zhang P.F. Study on basis of surveying adjustment teaching reform. Science of Mapping and Suveying, 2010(90)

[4] Qiu, W.N., Tao, B.X. and Yao, Y.B. Theory of errors and the construction and practice of basis of mapping and surveying adjustment quality course. Surveying and Mapping Engineering. 2011(2)

[5] Wang, X.J., Liang, Y.B. Teaching reform of surveying adjustment and construction of quality course construction. Mining Geodesy, 2010(2). 